\title{
Factors affecting zooplankton feeding by the sea anemone Aiptasia pallida
}

\author{
William S. Clayton, Jr. \\ Department of Microbiology, University of Maryland; \\ College Park, Maryland, 20742, U.S.A.
}

\begin{abstract}
Effects of various treatments on prey capture, prey ingestion and ingestion time of individual Artemia salina nauplii by the sea anemone Aiptasia pallida Verrill were studied in the laboratory. Exposure to crude Artemia homogenate, $5 \times 10^{-4} \mathrm{M}$ reduced glutathione or $5 \times 10^{-4} \mathrm{M}$ proline significantly decreased the number of Artemia that were captured and ingested but had no significant effect on the ingestion time of individual Artemia. Multiple captures increased the total ingestion time but decreased ingestion time per prey item. Results suggest that, under these conditions, the prey capture phase of zooplankton feeding was somewhat distinct from the ingestion phase since chemical stimuli that significantly reduced prey capture had no significant effect on ingestion time.
\end{abstract}

\section{INTRODUCTION}

Zooplankton feeding by cnidarians represents a major interaction of the organism with the environment. For example, the importance of zooplankton feeding in determining population size and individual growth has been repeatedly demonstrated in $H y d r a$ (Lenhoff \& Loomis, 1957; Muscatine, 1961; Slobodkin, 1964; Muscatine \& Lenhoff, 1965; Clayton, 1984), siphonophores (Purcell, 1981a, 1982), and anthozoans (Muscatine, 1961; Minasian, 1976, 1979, 1982; Sebens, 1980, 1981; Clayton \& Lasker, 1985).

Given the significance of zooplankton feeding for cnidarian growth and survival, much work has focused on the feeding process itself. The "feeding reflex" or "feeding response" refers to those behaviours that occur between prey capture and ingestion (Loomis, 1955; Lenhoff, 1961a) and has been thoroughly examined in many species. For example, factors that initiate the feeding response have been determined for Hydra (Loomis, 1955; Lenhoff, 1961a, b; Mariscal, 1971), hydroids (Lenhoff \& Schneiderman, 1959; Fulton, 1963; Pardy \& Lenhoff, 1968), siphonophores (Lenhoff \& Schneiderman, 1959; Mackie \& Boag, 1963), corals (Mariscal \& Lenhoff, 1968; Lehman \& Porter, 1973) and sea anemones (Lindstedt et al, 1968; Lindstedt, 1971; Reimer, 1971a, b, 1973; and many others). Many environmental parameters can affect the feeding response (Lenhoff, $1961 \mathrm{a}, \mathrm{b}, 1965)$ but it is uncertain whether nematocyst discharge and zooplankton feeding can be controlled, in any manner, by the individual (Picken \& Skaer, 1966; Mariscal, 1974).

Host control of nematocyst discharge and zooplankton feeding have been studied by examining individuals following the cessation of prey ingestion. For example, discharge 
of stenotele nematocysts, which are used for prey capture, decreases in Hydra when there is food in the gastrovascular cavity (Burnett et al., 1960; Hand, 1961). Feeding also inhibits subsequent nematocyst activity by sea anemones (Sandberg et al., 1971; Mariscal, 1973). In addition, fed Hydra exhibit a rise in the chemical threshold necessary to initiate feeding (Koizumi \& Maeda, 1981). It has been suggested that fed hydra may modify nematocyst action after stimulation of stretch receptors in the gastrovascular cavity (Burnett et al., 1960), following sensation of prey factors in the gastrovascular cavity (Smith et al., 1974), or from the accumulation of soluble factors in the environment (Ruch \& Cook, 1984).

Studies of those factors controlling zooplankton feeding have not considered effects on a central feeding parameter, the number of prey actually ingested. Clearly, this aspect of feeding is important since it represents the culmination of the feeding process and is fundamental for individual growth and survival. In addition, there is evidence that prey digestion can alter subsequent zooplankton feeding (Burnett et al., 1960; Hand, 1961; Smith et al., 1974; Lasker et al., 1982). In this study I examined the effects of various treatments on prey capture, prey ingestion and ingestion time by the sea anemone Aiptasia pallida. Results suggest that, under these conditions, zooplankton capture and ingestion can be modified by the individual while ingestion time remains unaltered.

\section{MATERIALS AND METHODS}

\section{Specimen maintenance}

Aiptasia pallida used in all experiments were derived, by pedal laceration, from a single individual initially obtained from Carolina Biological Supply Company. All individuals were symbiotic and contained zooxanthellae. Anemones were maintained in artificial sea water (Dayno Sea Salts) at $23 \pm 1{ }^{\circ} \mathrm{C}$ on a LD 14:10 photoperiod at a light intensity of $65 \mu \mathrm{E} \cdot \mathrm{m}^{-2} \cdot \mathrm{sec}^{-1}$. Individuals used in all experiments were starved for two days and were taken from cultures fed to repletion twice per week (Monday and Thursday) with freshly hatched $(24-48$ h) Artemia salina nauplii.

\section{Feeding experiments}

Individual anemones were placed in separate plastic cups with $40 \mathrm{ml}$ sea water and allowed to attach and expand (45-75 min). Fifty extensively washed Artemia salina nauplii were then presented singly using a Pasteur pipette. Each nauplius was repeatedly released near the tentacles until the nauplius swam into a tentacle (Ruch \& Cook, 1984). Impact of the nauplius with a tentacle is termed prey interception (Lasker et al., 1982). Following interception a nauplius was either: (1) captured and ingested; (2) captured but not ingested or; (3) not captured. Ingestion time of nauplii in the first category was arbitrarily defined as the time elapsed from first contact with a tentacle to closure of the mouth after ingestion. The second category includes nauplii that were killed and either remained on the tentacles or were subsequently released from the tentacles. Nauplii in the third category had to swim normally for at least thirty sec after interception to be considered not captured. 
Effects of crude Artemia homogenate, $5 \times 10^{-4} \mathrm{M}$ reduced glutathione (GSH) and $5 \times 10^{-4} \mathrm{M}$ proline on zooplankton feeding were also examined. $3 \mathrm{ml}$ of wetpacked Artemia (Slobodkin, 1964) were homogenized with a glass tissue grinder, filtered $(0.45 \mu \mathrm{m})$, and the filtrate used as chemical stimulus. GSH and proline were selected as chemical stimulants since they are known to elicit the feeding response in a variety of cnidarians (c.f. Loomis, 1955; Fulton, 1963; Lenhoff, 1961a, b; Lindstedt, 1971; Lehman \& Porter, 1973). Following a $15 \mathrm{~min}$ exposure to Artemia homogenate, $5 \times 10^{-4} \mathrm{M} \mathrm{GSH}$ or $5 \times 10^{-4} \mathrm{M}$ proline feeding experiments were conducted as described previously.

The relationship between number of prey captured and total ingestion time for all prey items was examined by presenting 2-8 Artemia near the tentacles of an individual anemone and determining the number captured and total ingestion time for all Artemia. The number of nauplii present in a multiple capture was defined as the total number captured by an anemone within 5 seconds of the first prey capture.

\section{RESULTS AND DISCUSSION}

Number of prey ingested by individual Aiptasia pallida (Table 1) was significantly less for anemones exposed to either crude Artemia homogenate $\left(t_{\mathrm{s}}=12.06 ; \mathrm{df}=8 ; \mathrm{p}\right.$ $<0.001), 5 \times 10^{-4} \mathrm{M} \mathrm{GSH}\left(\mathrm{t}_{\mathrm{s}}=12.59 ; \mathrm{df}=8 ; \mathrm{p}<0.001\right)$ or $5 \times 10^{-4} \mathrm{M}$ proline $\left(\mathrm{t}_{\mathrm{s}}=\right.$ 13.39; df $=8 ; \mathrm{p}<0.001$ ). However, ingestion time (Table 2) for those Artemia consumed

Table 1. Effects of various treatments on the fate of the first 50 intercepted Arternia salina nauplii by Aiptasia pallida $(\overline{\mathrm{X}} \pm \mathrm{s}$.d.). In all cases $\mathrm{n}=5$ anemones. Percent change column lists the percent difference of each treatment compared to the control for the number of nauplii captured and ingested

\begin{tabular}{|lccccc|}
\hline Treatment & $\begin{array}{l}\text { No. captured } \\
\text { and ingested }\end{array}$ & $\begin{array}{l}\text { No. only } \\
\text { captured }\end{array}$ & $\begin{array}{c}\text { No. not } \\
\text { captured }\end{array}$ & $\begin{array}{c}\% \\
\text { change }\end{array}$ & $p$ \\
\hline $\begin{array}{l}\text { Control } \\
\begin{array}{l}\text { Crude } \\
\text { homogenate }\end{array}\end{array}$ & $49.80 \pm 0.45$ & $0.20 \pm 0.45$ & $0.00 \pm 0.00$ & - & - \\
$\begin{array}{l}5 \times 10^{-4} \mathrm{M} \\
\mathrm{GSH}\end{array}$ & $25.06 \pm 4.44$ & $4.40 \pm 2.07$ & $20.54 \pm 5.18$ & -49.68 & $<0.001$ \\
$\begin{array}{l}5 \times 10^{-4} \mathrm{M} \\
\text { proline }\end{array}$ & $21.40 \pm 4.72$ & $5.60 \pm 3.21$ & $23.00 \pm 4.47$ & -57.03 & $<0.001$ \\
\hline
\end{tabular}

Table 2. Effects of various treatments on ingestion time (in sec) of Artemia salina nauplii by Aiptasia pallida ( $\overline{\mathrm{X}} \pm \mathrm{s}$. d.). In all cases $\mathrm{n}=5$ anemones. Percent change column lists the percent difference of each treatment compared to the control

\begin{tabular}{|lccc|}
\hline \multicolumn{1}{|c}{ Treatment } & Ingestion time & $\%$ change & $\mathrm{p}$ \\
\hline Control & $22.39 \pm 1.47$ & - & - \\
Crude homogenate & $21.98 \pm 2.25$ & -1.83 & $>0.50$ \\
$5 \times 10^{-4} \mathrm{M}$ GSH & $23.86 \pm 3.21$ & +6.57 & $>0.05$ \\
$5 \times 10^{-4} \mathrm{M}$ proline & $24.04 \pm 3.82$ & +7.37 & $>0.05$ \\
\hline
\end{tabular}


by anemones was not significantly affected by exposure to Artemia homogenate $\left(\mathrm{t}_{\mathrm{s}}=\right.$ $0.34 ; \mathrm{df}=8 ; \mathrm{p}>0.50), 5 \times 10^{-4} \mathrm{M} \mathrm{GSH}\left(\mathrm{t}_{\mathrm{s}}=1.91 ; \mathrm{df}=8 ; \mathrm{p}>0.05\right)$ or $5 \times 10^{-4} \mathrm{M}$ proline $\left(t_{s}=2.04 ; \mathrm{df}=8 ; \mathrm{p}>0.05\right)$. There was a significant positive correlation between the number of prey captured and total ingestion time for anemones with multiple Artemia captures (Fig. 1; r $=0.92 ; \mathrm{p}>0.001$ ).

Zooplankton feeding by cnidarians can be divided into a series of discrete actions (Forest, 1962; Lenhoff, 1974; Lasker et al., 1982). The first step is the impact, or interception, of a prey item with a tentacle. Following interception, the prey item may, or may not, be captured as a result of nematocyst discharge. Failure to capture prey may due to nematocyst inactivation or previous nematocyst depletion. In these experiments, a 15 min treatment with crude Artemia homogenate, $5 \times 10^{-4} \mathrm{M} \mathrm{GSH}$ or $5 \times 10^{-4} \mathrm{M}$ proline decreased prey capture and ingestion by $49.68,59.46$ and $57.03 \%$ respectively (Table 1). Decreased zooplankton feeding may have been due to the presence of fewer functional nematocysts in treated anemones since Artemia homogenate is known to elicit appreciable nematocyst discharge (Pantin, 1942; Burnett et al., 1963; Ruch \& Cook, 1984). Reduction in number of prey captured and ingested following exposure to

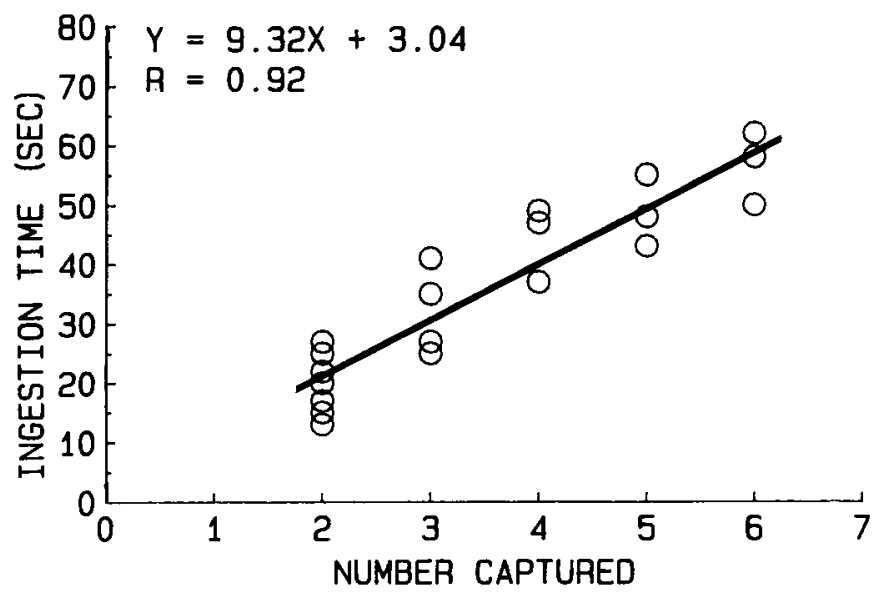

Fig. 1. Total ingestion time (Y) as a function of the number of prey captured (X)

Artemia homogenate suggests that zooplankton feeding is, in some manner, determined by the chemical stimulation of intercepted prey. However, chemical stimulation alone did not totally extinguish zooplankton feeding (Table 1), indicating that feeding is not only controlled by chemical stimulation (Lasker et al., 1982).

Although chemical stimulation reduced zooplankton capture and ingestion (Table 1), it had no effect on the ingestion time of Artemia (Table 2). This suggests that the prey ingestion phase of zooplankton feeding is distinct from the prey capture phase (Lenhoff, 1974; Lasker et al., 1982) since one (zooplankton capture) was reduced by chemical stimulation while the other (ingestion time) was not. Lindstedt (1971) has shown a similar response in Anthopleura elegantissima, where tentacle bending toward the mouth and prey ingestion following contact with the mouth are controlled by different chemical activators. 
Examination of those factors which initiate the specific phases of zooplankton feeding may play a role in understanding the mechanisms which control zooplankton feeding. For example, prey ingestion is clearly related to prey capture (Lasker et al., 1982; Clayton, 1984). However, if the ingestion phase and capture phase are activated by different factors then zooplankton feeding may be controlled primarily by prey capture since the number of prey captured can be reduced by chemical treatments similar to those that occur during zooplankton feeding (Lasker et al., 1982; Ruch \& Cook, 1984; Table 1) without altering the time required for ingestion (Table 2).

Prey capture partially determines the number of prey ingested (Lasker et al., 1982; Clayton, 1984). In Hydra viridis the number of prey ingested increases as the number captured increases while the length of the feeding response is unaltered (Lasker et al., 1982). Thus more prey are ingested during the same time period of the feeding response by an increase in ingestion rate and a decrease in the ingestion time for each prey item (Lasker et al., 1982). In these experiments, ingestion time was positively correlated with the number of prey in a multiple capture (Fig. 1). However, the total ingestion time for multiple captures could not be used to predict the ingestion time for a single capture. For example, the mean ingestion time for a single capture was $22.39 \mathrm{sec}$ (Table 2), which is considerably longer than the calculated ingestion time for a single capture of $12.36 \mathrm{sec}$ using the linear regression equation of $\mathrm{Y}=9.32 \mathrm{X}+3.04(\mathrm{Y}=$ ingestion time; $\mathrm{X}=$ number captured; from Fig. 1). However, mean ingestion time for a single capture is very similar to the calculated ingestion time for two prey items $(21.68 \mathrm{sec})$, suggesting that one or two Artemia require approximately the same amount of time for ingestion. In contrast, the calculated ingestion time for six prey items (from Fig. 1) is 58.96 sec, which is markedly less than the sum of the ingestion times for six separate prey items $(6 \times 22.39 \mathrm{sec}=134.34 \mathrm{sec})$. Thus the ingestion phase, which was unaffected by chemical stimulation (Table 1), was modified by multiple captures. During a feeding bout, when multiple captures occur, the ingestion rate (i.e. number of prey ingested/sec) apparently increases (c.f. Lasker et al., 1982), since the ingestion time for more than two prey would be less than the sum of the individual ingestion times for that many separate prey items.

This characteristic of zooplankton feeding could permit benthic cnidarians to ingest more prey, in a set time interval, when prey capture is high. Prey capture would be expected to be greatest during periods of high prey density since the number of prey ingested is directly related to prey density (Lasker, 1976; Purcell, 1981b, 1982; Clayton \& Lasker, 1982; Bailey \& Batty, 1983). Dense concentrations of marine zooplankton routinely occur near the substrate (Emery, 1968; Alldredge \& King, 1977), which raises the possibility that increased ingestion rate during periods of high prey capture may enhance feeding capability (i.e. number of prey ingested) when prey are present in large numbers.

Zooplankton feeding may be viewed as the integration of several distinct behaviors, some of which may be affected by the feeding process itself. In these experiments, various treatments affected the number of zooplankton captured (Table 1) but not ingestion time (Table 2), suggesting that the capture phase of zooplankton feeding is distinct from the ingestion phase of the feeding process. Ingestion time was positively correlated with the number of prey captured and ingested (Fig. 1) but calculations indicate that multiple captures resulted in a decrease in the ingestion time for each prey 
item. Thus ingestion time was unaffected by treatments that reduced zooplankton capture but was modified by the individual in response to multiple captures. Only further studies of the various phases of zooplankton feeding, and their relationship to each other, will yield a thorough understanding of the controlling mechanisms of zooplankton feeding.

Acknowledgements. I thank $\mathrm{H}$, Lasker for valuable discussion and advice. L. Scrocchi and $\mathrm{R}$. Beauchamp graciously assisted in the laboratory.

\section{LITERATURE CITED}

Alldredge, A. A. \& King, J. M., 1977. Distribution, abundance and substrate preferences of demersal reef zooplankton at Lizard Is., Great Barrier Reef. - Mar. Biol. 41, 317-334.

Bailey, K. M. \& Batty, R. S., 1983. A laboratory study of predation by Aurelia aurita on larval herring: Experimental observations compared with model predictions. - Mar. Biol. 72, 295-301.

Burnett, A. L., Lentz, T. \& Warren, M., 1960. The question of control of the nematocyst discharge reaction by fully fed hydra. - Annls Soc. r. zool. Belg. 90, 247-268.

Burnett, A. L., Davidson, R. \& Wiernik, P., 1963. On the presence of a feeding hormone in the nematocyst of Hydra pirardi. - Biol. Bull. mar. biol. Lab., Woods Hole 125, 226-233.

Clayton, W. S., Jr., 1984. Effects of altered light and feeding regimes on the zooplankton feeding capability of Hydra viridis. - Int. Revue ges. Hydrobiol. 69, 633-642.

Clayton, W. S., Jr. \& Lasker, H. R., 1982. Effects of light and dark treatments on feeding by the reef coral Pocillopora damicornis. - J. exp. mar. Biol. Ecol. 62, 269-279.

Clayton, W. S., Jr. \& Lasker, H. R., 1985. Individual and population growth in the asexually reproducing anemone Aiptasia pallida. - J. exp. mar. Biol. Ecol. 90, 249-258.

Emery, A. R., 1968. Preliminary observations on coral reef plankton. - Limnol. Oceanogr. 13, 293-304.

Forest, $H_{.}, 1962$. Lack of dependence of the feeding reactions in hydra on reduced glutathione. Biol. Bull. mar. biol. Lab., Woods Hole 122, 343-361.

Fulton, C., 1963. Proline control of the feeding reaction of Cordylophora. - J. gen. Physiol. 46, $493-506$.

Hand, C., 1961. Present state of nematocyst research: Types, structure and function. In: The biology of Hydra. Ed. by H. M. Lenhoff \& W. F. Loomis. Univ. of Miami Press, Miami, 187-202.

Koizumi, O. \& Maeda, N., 1981. Rise of feeding threshold in satiated Hydra. - J. comp. Physiol. 142, 75-80.

Lasker, H. R., 1976. Intraspecific variability of zooplankton feeding in the hermatypic coral Montastrea cavernosa. In: Coelenterate ecology and behavior. Ed. by G. O. Mackie. Plenum Press, New York, 101-109.

Lasker, H. R., Syron, J. A. \& Clayton, W. S., Jr., 1982. The feeding response of Hydra viridis: Effects of prey density on capture rates. - Biol. Bull. mar, biol. Lab., Woods Hole 162, 290-298.

Lehman, J. T. \& Porter, J. W., 1973. Chemical activation of feeding in the Caribbean reef-building coral Montastrea cavernosa. - Biol. Bull. mar. biol. Lab., Woods Hole 145, 140-149.

Lenhoff, H. M., 1961a. Activation of the feeding reflex in Hydra littoralis. In: The biology of Hydra. Ed. by H. M. Lenhoff \& W. F. Loomis. Univ. of Miami Press, Miami, 203-232.

Lenhoff, H. M., 1961 b. Activation of the feeding reflex in Hydra littoralis. I. Role played by reduced glutathione and quantitative assay of the feeding reflex. - J. gen. Physiol. 45, 331-344.

Lenhoff, H. M., 1965. Some physiochemical aspects of the macro and microenvironments surrounding hydra during activation of their feeding response. - Am. Zool. 5, 515-524.

Lenhoff, H. M, 1974. On the mechanism of action and evolution of receptors associated with feeding and digestion. In: Coelenterate biology: Reviews and new perspectives. Ed. by L. Muscatine \& H. M. Lenhoff. Acad. Press, New York, 211-243.

Lenhoff, H. M. \& Loomis, W. F., 1957. Environmental factors controlling respiration in hydra. $-J$. exp. Zool. 134, 171-182. 
Lenhoff, H. M. \& Schneiderman, H. A., 1959. The chemical control of feeding in the Portuguese man-of-war, Physalia physalis and its bearing on the evolution of the Cnidaria. - Biol. Bull. mar. biol. Lab., Woods Hole 116, 452-460.

Lindstedt, K. J., 1971. Biphasic feeding response in a sea anemone: Control by asparagine and glutathione. - Science, N. Y. 173, 33-334.

Lindstedt, K. J., Muscatine, L. \& Lenhoff, H. M., 1968. Valine activation of feeding in the sea anemone Boloceroides. - Comp. Biochem. Physiol. 26, 567-572.

Loomis, W. F., 1955. Glutathione control of the specific feeding reactions of Hydra. - Ann. N. Y. Acad. Sci. 62, 209-228.

Mackie, G. O.\& Boag, D. A., 1963. Fishing, feeding, and digestion in siphonophores. - Pubbl. Staz. zool. Napoli 33, 178-196.

Mariscal, R. N., 1971. A note on the glutathione control of feeding in Chlorohydra viridissima. In: Experimental coelenterate biology. Ed. by H. M. Lenhoff, L. Muscatine \& L. Davis. Univ. of Hawaii Press, Honolulu, 116-118.

Mariscal, R. N., 1973. The control of nematocyst discharge during feeding by sea anemones. - Publs Seto mar. Biol. Lab. 20, 695-702.

Mariscal, R. N., 1974. Nematocysts. In: Coelenterate biology: Reviews and new perspectives. Ed. by L. Muscatine \& H. M. Lenhoff. Acad. Press, New York, 129-179.

Mariscal, R. N. \& Lenhoff, H. M., 1968. The chemical control of feeding behavior in Cyphastrea ocellina. - J. exp. Biol. 49, 689-699.

Minasian, Jr., L. L., 1976. Characteristics of asexual reproduction in the sea anemone Haliplanella luciae. In: Coelenterate ecology and behavior. Ed, by G. O. Mackie. Plenum Press, New York, $289-298$

Minasian, Jr., L. L., 1979. The effect of exogenous factors on morphology and asexual reproduction in laboratory cultures of the intertidal sea anemone, Haliplanella luciae from Delaware. - J. exp. mar. Biol. Ecol. 40, 235-246.

Minasian, Jr., L. L., 1982. The relationship of size and biomass to fission rate in a clone of the sea anemone, Haliplanella luciae. - J. exp. mar. Biol. Ecol. 58, 151-162.

Muscatine, L., 1961. Symbiosis in marine and freshwater coelenterates. In: The biology of Hydra. Ed. by H. M. Lenhoff \& W. F. Loomis. Univ, of Miami Press, Miami, 255-268.

Muscatine, L. \& Lenhoff, H. M., 1965. Symbiosis of hydra and algae. II. Effects of limited food and starvation on the growth of symbiotic and aposymbiotic hydra. - Biol. Bull. mar. biol. Lab., Woods Hole 129, 316-328.

Pantin, C. F. A., 1942. The excitation of nematocysts. - J. exp. Biol. 19, 294-310.

Pardy, R. H. \& Lenhoff, H. M., 1968. The feeding biology of the gymnoblastic hydroid, Pennaria tiarella. - J. exp. Zool. 168, 197-202.

Picken, L. E. R. \& Skaer, R. J., 1966. A review of researches on nematocysts. - Symp. zool. Soc. Lond. $16,19-50$.

Purcell, J, E., 1981a. Feeding ecology of Rhizophysa eysenhardti, a siphonophore predator of fish larvae. - Limnol. Oceanogr. 26, 424-432.

purcell, J. E., $1981 \mathrm{~b}$. Dietary composition and diel feeding patterns of epipelagic siphonophores.Mar. Biol. 65, 83-90.

Purcell, J. E., 1982. Feeding and growth of the siphonophore Muggiaea atlantica. - J. exp. mar. Biol. Ecol. 62, 39-54.

Reimer, A. A, 1971a. Chemical control of feeding behavior in Palythoa.-Comp. Biochem. Physiol. $40 \mathrm{~A}, 19-38$.

Reimer, A. A., $1971 \mathrm{~b}$. Specificity of feeding chemoreceptors in Palythoa psammophilia. - Comp. gen. Pharmac. 2, 383-396.

Reimer, A. A., 1973. Feeding behavior in the sea anemone Calliactis polypus.-Comp. Biochem. Physiol. 44 A, 1289-1301.

Ruch, R. J. \& Cook, C. B., 1984. Nematocyst discharge during feeding in Hydra littoralis. - J. exp. Zool. $111,31-42$.

Sandberg, D. M., Kanciruk, P. \& Mariscal, R. N., 1971. Inhibition of nematocyst discharge correlated with feeding in the sea anemone Calliactis tricolor. - Nature, Lond. 232, 263-264.

Sebens, K. P., 1980. The regulation of asexual reproduction and indeterminate body size in the sea anemone Anthopleura elegantissima. - Biol. Bull. mar. biol. Lab., Woods Hole 158, $370-382$. 
Sebens, K. P., 1981. The allometry of feeding, energetics, and body size in three sea anemone species. - Biol. Bull. mar. biol. Lab., Woods Hole 161, 152-171.

Slobodkin, L. B., 1964. Experimental populations of hydrida. - J. Ecol. (Suppl.) 52, 131-148.

Smith, S., Oshida, J. \& Bode, H., 1974. Inhibition of nematocyst discharge in hydra fed to repletion.Biol. Bull. mar, biol. Lab., Woods Hole 147, 186-202. 